Article

\title{
CuO Thin Films Functionalized with Gold Nanoparticles for Conductometric Carbon Dioxide Gas Sensing
}

\author{
Robert Wimmer-Teubenbacher ${ }^{1, *}$, Florentyna Sosada-Ludwikowska ${ }^{1}$, \\ Bernat Zaragoza Travieso ${ }^{1}$, Stefan Defregger ${ }^{1}$, Oeznur Tokmak ${ }^{2}$, Jan Steffen Niehaus ${ }^{2}$, \\ Marco Deluca ${ }^{1}$ and Anton Köck ${ }^{1}$ \\ 1 Materials Center Leoben Forschung GmbH, A-8700 Leoben, Austria; \\ florentyna.sosada-ludwikowska@mcl.at (F.S.-L.); bernat.zaragoza-travieso@mcl.at (B.Z.T.); \\ stefan.defregger@mcl.at (S.D.); marco.deluca@mcl.at (M.D.); anton.koeck@mcl.at (A.K.) \\ 2 Fraunhofer-Institut für Angewandte Polymerforschung IAP-CAN, D-20146 Hamburg, Germany; \\ oeznur.tokmak@iap.fraunhofer.de (O.T.); jan.steffen.niehaus@iap.fraunhofer.de (J.S.N.) \\ * Correspondence: robert.wimmer-teubenbacher@mcl.at; Tel.: +43-3842-4592-234
}

Received: 28 August 2018; Accepted: 21 November 2018; Published: 22 November 2018

\begin{abstract}
Metal oxides (MOx) are a well-established material for gas sensing. MOx-based gas sensors are sensitive to a wide variety of gases. Furthermore, these materials can be applied for the fabrication of low-cost and -power consumption devices in mass production. The market of carbon dioxide $\left(\mathrm{CO}_{2}\right)$ gas sensors is mainly dominated by infra-red (IR)-based gas sensors. Only a few MOx materials show a sensitivity to $\mathrm{CO}_{2}$ and so far, none of these materials have been integrated on CMOS platforms suitable for mass production. In this work, we report a cupric oxide $(\mathrm{CuO})$ thin film-based gas sensor functionalized with gold $(\mathrm{Au})$ nanoparticles, which exhibits exceptional sensitivity to $\mathrm{CO}_{2}$. The $\mathrm{CuO}$-based gas sensors are fabricated by electron beam lithography, thermal evaporation and lift-off process to form patterned copper $(\mathrm{Cu})$ structures. These structures are thermally oxidized to form a continuous $\mathrm{CuO}$ film. Gold nanoparticles are drop-coated on the $\mathrm{CuO}$ thin films to enhance their sensitivity towards $\mathrm{CO}_{2}$. The $\mathrm{CuO}$ thin films fabricated by this method are already sensitive to $\mathrm{CO}_{2}$; however, the functionalization of the $\mathrm{CuO}$ film strongly increases the sensitivity of the base material. Compared to the pristine $\mathrm{CuO}$ thin film the $\mathrm{Au}$ functionalized $\mathrm{CuO}$ film shows at equal operation temperatures $\left(300^{\circ} \mathrm{C}\right)$ an increase of sensitivity towards the same gas concentration (e.g., $2000 \mathrm{ppm}$ $\mathrm{CO}_{2}$ ) by a factor of 13 . The process flow used to fabricate $\mathrm{Au}$ functionalized $\mathrm{CuO}$ gas sensors can be applied on CMOS platforms in specific post processing steps.
\end{abstract}

Keywords: metal oxides; gas sensors; $\mathrm{CuO} ; \mathrm{CO}_{2} ; \mathrm{CMOS}$ integration

\section{Introduction}

Natural emissions of carbon dioxide $\mathrm{CO}_{2}$ in Earth's atmosphere can be referenced to the carbon cycle. Man-made or anthropogenic $\mathrm{CO}_{2}$ emissions can be mainly attributed to the combustion of fossil fuels in transport, industry, and electricity [1]. Over the last two centuries the carbon dioxide concentration has risen from an average value of approximately $280 \mathrm{ppm}$ [2] (pp. 4-6) to a value about $411 \mathrm{ppm}$ [3]. Apart from this alarming trend, $\mathrm{CO}_{2}$ has a significant direct impact to human health and thus plays an important role for indoor air quality monitoring. The main source of the indoor $\mathrm{CO}_{2}$ concentration is the metabolism of the occupants, who continuously exhale a steady amount of $\mathrm{CO}_{2}$, that is added to the base global $\mathrm{CO}_{2}$ concentration, setting the lower level for the indoor concentration. An elevated indoor $\mathrm{CO}_{2}$ level causes significant symptoms for humans: reduction of mental concentration, fatigue, headache, and dizziness [4]. Extreme conditions, such 
as agricultural silo accidents, can even lead to death. Application of $\mathrm{CO}_{2}$ gas sensors in heating, ventilation, and air conditioning systems (HVAC) improves indoor air quality and thus the comfort for its occupants. Moreover, precise control of HVAC by air quality monitoring sensors-in particular, $\mathrm{CO}_{2}$ sensors-would strongly reduce the overall energy consumption of those systems. According to Nassif [5] the energy consumption of regular HVAC systems can be potentially decreased by $25 \%$ by switching to intelligent $\mathrm{CO}_{2}$ controlled HVACs, which would have a great impact on the global $\mathrm{CO}_{2}$ emissions and thus the outdoor $\mathrm{CO}_{2}$ levels. Currently available commercial $\mathrm{CO}_{2}$ gas sensors, which measure the $\mathrm{CO}_{2}$ concentration directly, are mostly based on optical (infra-red) detection [6] employing an IR emitter and a detector with a specific absorption length in between. The advantages of these sensors are their precision, resolution, and robustness. The disadvantages are their size (several $\mathrm{cm}$ ), high power consumption and comparatively high cost. At research level a lot of effort is put into the exploitation of new approaches for optical $\mathrm{CO}_{2}$ sensors $[7,8]$, in particular with respect to miniaturization. Employment of wave-guides and integration on silicon or even CMOS devices might reduce size and power consumption; however, the optical principle requires a minimum absorption length, which prevents significant miniaturization. A promising alternative to optical sensors are conductometric chemical sensors. A variety of established sensors already exist on the market, which can detect various target gases, such as $\mathrm{CO}, \mathrm{H}_{2}$ or Volatile Organic Compounds (VOCs).

In literature various material types exhibiting sensitivity towards $\mathrm{CO}_{2}$ are reported: metal organic framework [9], nascion [10], perovskite [11], solid electrochemical type [12]. The most prominent class of materials for gas sensing are metal oxide materials, which exhibit high sensitivity towards numerous gases, but in general hardly any to $\mathrm{CO}_{2}$. For the following metal oxides a sensitivity to $\mathrm{CO}_{2}$ has been reported: $\mathrm{Gd}$-doped $\mathrm{CeO}_{2}$ [13], $\mathrm{Pd}$-doped $\mathrm{La}_{2} \mathrm{O}_{3}$ [14], nano-particulate $\mathrm{CuO}$ films [15,16] and $\mathrm{BaTiO}_{3}-\mathrm{CuO}$ films [17]. However, up to now no electrical sensor capable to directly detect $\mathrm{CO}_{2}$ is available as a commercial product.

In this work, we present $\mathrm{CuO}$ thin film sensors fabricated by thermal oxidation of patterned copper layers. The sensitivities of the pristine $\mathrm{CuO}$ sensors and sensors functionalized with gold $(\mathrm{Au})$ nanoparticles have been evaluated towards $\mathrm{CO}_{2}$ at different humidity levels. While the pristine $\mathrm{CuO}$ sensor has a maximum response of $32 \%$ at $350{ }^{\circ} \mathrm{C}$, the $\mathrm{Au}$ functionalization of the $\mathrm{CuO}$ sensor leads to an exceptional increase of the response by a factor of 11 up to $365 \%$ at $300{ }^{\circ} \mathrm{C}$. To our best knowledge this is one of the highest responses ever reported for a conductometric $\mathrm{CO}_{2}$ sensor. Table A1 shows some of the highest $\mathrm{CO}_{2}$ responses for metal oxide-based sensors in literature compared to this work. One of the most important features of our sensor device is that the entire process flow enables an integration on CMOS devices.

\section{Materials and Methods}

\subsection{Gas Sensor Fabrication}

The gas sensor is fabricated using a five-step process: (1) electrode deposition, (2) fabrication of a patterned copper $(\mathrm{Cu})$ layer, (3) sensor stack assembly, (4) thermal oxidation and (5) nanoparticles functionalization. All the essential parameters of the fabrication process have been optimized to enable subsequent integration on CMOS devices.

1. The base substrate for fabricating the gas sensors is a silicon substrate with a thermal silicon oxide layer of $300 \mathrm{~nm}$ on top (SIEGERT WAFER GmbH). Gold electrodes are employed to electrically contact the $\mathrm{CuO}$ sensing film. The fabrication of the electrode system is done by photolithography with a positive photoresist (AZ ${ }^{\circledR}$ MIR701, Microchemicals, EVG 620 Mask aligner) and thermal evaporation (Univex Evaporator 450 by Leybold $\mathrm{GmbH}$ ) of $5 \mathrm{~nm}$ thick titanium layer and a gold layer of $200 \mathrm{~nm}$ thickness as electrode material. The lift-off process is realized by submerging the substrate in acetone for a duration of $12 \mathrm{~h}$ (see Table A2 in appendix for the applied process parameters). The geometry of the electrode system is designed to enable four-point measurement (see Figure 1b) and to ensure precise electrical resistance measurements. 
2. In the second step the $\mathrm{Cu}$-films are deposited on top of the Ti/Au electrode system. For this a $60 \mu \mathrm{m}$ by $25 \mu \mathrm{m}$ structure is exposed by electron beam lithography (Raith eLINE plus, positive electron beam resist AR-P 672.08, ALLRESIST GmbH) into the resist. The structure itself is subdivided into six strips, which are separated by a distance of $2.25 \mu \mathrm{m}$. After resist development, a Ti adhesion layer (thickness $5 \mathrm{~nm}$ ) and a Cu layer (thickness $500 \mathrm{~nm}$ ) are deposited by thermal evaporation (Univex Evaporator 450, Leybold $\mathrm{GmbH}$ ). The lift-off process is realized by submerging the entire substrate in acetone for $4 \mathrm{~h}$.

3. In the third step the assembly of the gas sensor stack is performed. Metal oxide gas sensors need to be operated at higher temperatures $\left(200^{\circ} \mathrm{C}-400^{\circ} \mathrm{C}\right)$. Therefore, the sensor stack, containing the substrate with $\mathrm{Ti} / \mathrm{Au}$ electrode system and the $\mathrm{Cu}$ layer (as precursor for $\mathrm{CuO}$ ), must be merged with a heater and a thermocouple. The heater consists of two Pt 6.8 elements (Delta-R GmbH) connected in series; a Pt100 element (Delta-R GmbH) is used as the thermocouple to monitor operation temperature. The sensors are glued with both heater elements and thermocouple to a sensor system with thermoconductive adhesive (Aremco Ceramabond 865, Aremco Products Inc.). The final device is soldered, and wire bonded to a custom-made printed circuit board (PCB) as shown in Figure 1a.

4. The fourth step addresses the thermal oxidization of the $\mathrm{Cu}$ metal layer, which is performed in situ in the gas measurement set-up (GMS). The atmospheric condition in the GMS is provided by synthetic air (Linde Gas $\mathrm{GmbH}$ ) with relative humidity level $(\mathrm{rH})$ of $50 \%$. For a duration of six hours the gas sensor is heated at a constant temperature of $400{ }^{\circ} \mathrm{C}$, which results in oxidation of the $\mathrm{Cu}$ layer. The entire $\mathrm{Cu}$ metal layer is oxidized to form a continuous $\mathrm{CuO}$ film.

5. The sensor fabrication is finalized in the fifth step by functionalizing the $\mathrm{CuO}$ film with $\mathrm{Au}$ nanoparticles (Au-NPs). This is performed by stepwise drop coating a volume of $5 \mu \mathrm{L}$ of an aqueous Au-NPs solution (CANdot ${ }^{\circledR}$ Series G, c $=100 \mu \mathrm{g} \mathrm{Au} / \mathrm{mL}$, Fraunhofer IAP-CAN) onto the sensor surface. To ensure a fast evaporation of the solvent during nanoparticles deposition, the sensor is heated up to $85^{\circ} \mathrm{C}$. This is repeated several times; each consecutive step is started once the solvent is evaporated.

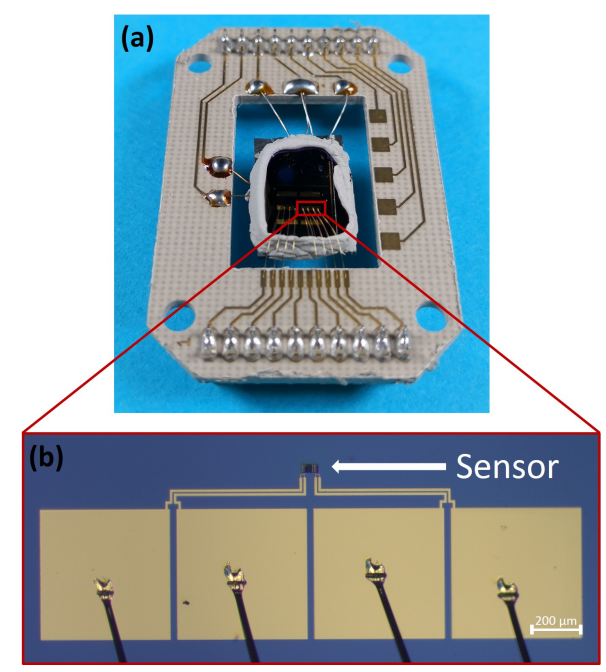

Figure 1. (a) Evaluation board with soldered heater and thermocouple and wire bonded gas sensor stack. (b) Wire bonded gas sensors with electrode system.

\subsection{Sensitivity Calculation and Data Evaluation}

The gas sensors sensitivity is determined by Equation (1). Herein, the resistance of the gas sensors in synthetic air is $R_{\text {air }}$, whereas the highest resistance value during gas exposure is $R_{\text {gas }}$. The sensitivity is a measure of the gas sensors' response towards a specific target gas at a specific concentration, humidity level and the operation temperature of the gas sensor. 


$$
S[\%]=\frac{\left(R_{g a s}-R_{a i r}\right)}{R_{\text {air }}} \cdot 100
$$

\subsection{Scanning Electron Beam Microscopy}

The scanning electron microscopy (SEM) investigation was done on an Auriga ${ }^{\circledR}$-CrossBeam ${ }^{\circledR}$ Workstation (Carl Zeiss Microscopy $\mathrm{GmbH}$ ) with an acceleration voltage of $10 \mathrm{keV}$. The surface investigations at high magnification and the elemental mapping were done on a ZEISS GeminiSEM 450 at $3 \mathrm{keV}$ and $5 \mathrm{keV}$.

\subsection{Raman Spectroscopy}

The Raman spectrum was measured with LabRAM HR800 from Horiba Jobin Yvon. A green $(514.5 \mathrm{~nm})$ Ar-ion laser in backscattering geometry was used as an excitation source. The analysis of the Raman signal was performed with a grating $(1800 \mathrm{~g} / \mathrm{mm})$, whereas the signal detection was done by a multichannel CCD.

\subsection{Gas Measurements Set-Up}

The GMS used in this work is a custom-made system capable of chemical sensor evaluation in a controlled and adjustable mixture of gases. The GMS consists of two parts: the gas atmospheric part and the electrical evaluation part.

The gas atmospheric part shown in Figure A1a enables precise control of the concentrations of two different test gases and the relative humidity $(\mathrm{rH})$ levels of the background gas. Since the goal is to simulate an ambient atmosphere, synthetic air $\left(20 \% \mathrm{O}_{2}, 80 \% \mathrm{~N}_{2}\right.$, Linde Gas $\left.\mathrm{GmbH}\right)$ is used as background gas. The background gas is set by two mass flow controllers (type: EL-FLOW, Bronkhorst High-Tech B.V.). The first mass flow controller is providing dry air, whereas the second mass flow controller is providing wet air, formed by bubbling part of the synthetic air through a container filled with deionized water. The two outputs of the dry and wet air are mixed to provide specific $\mathrm{rH}$ levels in the range of $10 \%-90 \% \mathrm{rH}$, which is measured using a commercial, humidity sensors (type: AFK-E, KOBOLD Holding Gesellschaft m.b.H.). Similar to the background gas the flows of each of the two test gases are set by three independent mass flow controllers (type: EL-FLOW, Bronkhorst High-Tech B.V.) to provide a wide adjustable range of concentrations. Each of these three mass flow controllers is calibrated for a specific concentration range to provide precision and range for varying test plan requirements. The background gas and the test gases are mixed before being introduced into the measurement chamber, which is an air-tight sealed stainless steel tube holding a volume of approximately $80 \mathrm{~cm}^{3}$. Our specific GMS is designed for a constant flow of $1000 \mathrm{sccm}$ to ensure an optimal gas injection into the measurement chamber. The gas is flowing parallel to the sensor surface. The sensor stack (see Figure 1) has a comparatively high thermal mass and no cooling effect was observed. Moreover, the Pt100 element provides a feedback loop to keep the sensor stack at a constant temperature.

The electrical evaluation part of the GMS (see Figure A1b) is designed for measuring the electrical resistance of the gas sensor, for operating the heater and for measuring the operation temperature of the entire sensor stack via voltage measurement of the thermocouple. The gas sensor resistance is measured by employing a source measure unit (type: 2400 SourceMeter SMU, Keithley). The heater is operated by a voltage source (type: PL330P, Thurlby Thandar Instruments). The voltage measurement of the thermocouple is done by a digital multimeter (type: 34401A, Keysight technologies). Both parts of the GMS are joined by a LabView program, wherein specific test plans can be defined. 


\section{Results}

\subsection{Copper Oxide Characterization}

The evaluation of the gas sensitive copper oxide film was done by SEM and Raman spectroscopy. Figure 2a shows the oxidized surface of the copper structures. The initial Cu strips can still be seen suggestively as vertical lines; however, thermal oxidation results in swelling of the $\mathrm{Cu}$ structures, the gaps between the separated $\mathrm{Cu}$ stripes are closed, electrically connected and a continuous film of copper oxide is formed. The oxidation parameters $\left(\mathrm{T}_{\text {Oxidation }}=400{ }^{\circ} \mathrm{C} / \mathrm{rH}=50 \% / \mathrm{t}=6 \mathrm{~h}\right.$ ) were chosen to result in the formation of a $\mathrm{CuO}$ film instead of $\mathrm{CuO}$ nanowires. Figure 3 shows a representative SEM image of the sensor surface, where the bright spots indicate the Au-NPs. A TEM picture of a Au-NP having an average diameter of $20 \mathrm{~nm}$ is shown in the insert. The SEM image shows both single Au-NPs on the $\mathrm{CuO}$ surface as well as agglomerated Au-NPs. To analyze the material composition and confirm the materials responsible for the chemical sensing mechanism at the sensor's surface, an elemental mapping has been performed in the $4 \mu \mathrm{m} \times 4 \mu \mathrm{m}$ section of the sensor surface as shown in Figure 3. The elemental mapping was done for four elements and is presented in Figure 4: (a) gold Au, (b) copper $\mathrm{Cu}$, (c) oxygen $\mathrm{O}$ and (d) silicon Si. The contrast of each color corresponds to the occurrence of the element. The SEM picture shows multiple nanoparticles on the sensor surface, high contrast. The Au elemental map clearly shows the highest contrast for Au at the same bright structures, which are shown in Figure 3 as Au-NPs. In both the $\mathrm{Cu}$ and the $\mathrm{O}$ elemental maps voids can be clearly seen at the location of these Au-NPs. Figure $4 \mathrm{~d}$ presents the elemental mapping of Si, where the occurrence of $\mathrm{Si}$ is a result of silicon diffusion during the oxidation process. Figure 5 shows an EDX of one of the Au-NPs, which clearly indicates that these nanoparticles are made of Au.

The identification of the copper oxide state $\left(\mathrm{CuO}\right.$ or $\left.\mathrm{Cu}_{2} \mathrm{O}\right)$ was performed by Raman spectroscopy. $\mathrm{CuO}$ possesses 12 phonon modes due to the presence of four atoms in the primitive unit cell. Factor group analysis gives [18]:

$$
\Gamma_{v i b r}=A_{g}+2 B_{g}+4 A_{u}+5 B_{u^{\prime}}
$$

of which only the three $\mathrm{A}_{g}$ and $\mathrm{B}_{g}$ modes are Raman-active. The Raman spectrum of $\mathrm{CuO}$ presents a strong $A_{g}$ mode at $296 \mathrm{~cm}^{-1}$ and two $B_{g}$ modes at $346 \mathrm{~cm}^{-1}$ and $631 \mathrm{~cm}^{-1}$. These modes involve only the vibrations of oxygen atoms in the direction of the $b$-axis of the unit cell for $A_{g}$ and perpendicular to the $b$-axis for $B_{g}$ modes [18]. Figure $2 b$ presents the Raman spectrum measured on the thermally oxidized film. The assignment of the Raman modes confirms that only $\mathrm{CuO}$ (one $\mathrm{A}_{g}$ mode and two $\mathrm{B}_{g}$ modes compatible with the positions reported in literature) is present-other copper oxide species cannot be evidenced from the measured spectrum. $\mathrm{Cu}_{2} \mathrm{O}$ and $\mathrm{Cu}_{4} \mathrm{O}_{3}$, in fact, present distinctive modes at $150 \mathrm{~cm}^{-1}, 220 \mathrm{~cm}^{-1}$ and $541 \mathrm{~cm}^{-1}$, respectively [18], which were not detected on the oxidized $\mathrm{CuO}$ film.
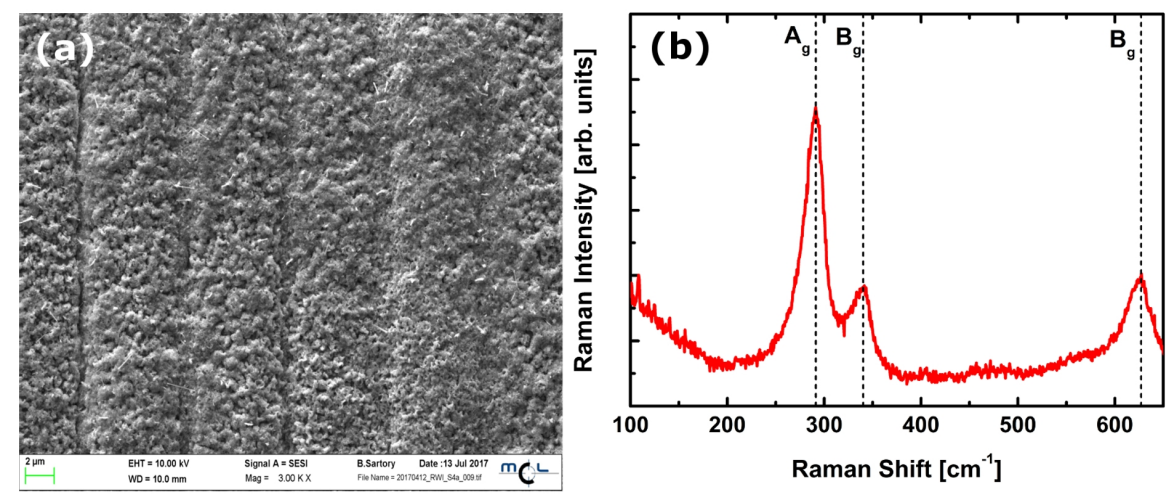

Figure 2. (a) SEM picture of the thermally oxidized CuO film. (b) Raman spectrum of the thermally oxidized $\mathrm{CuO}$ film. 


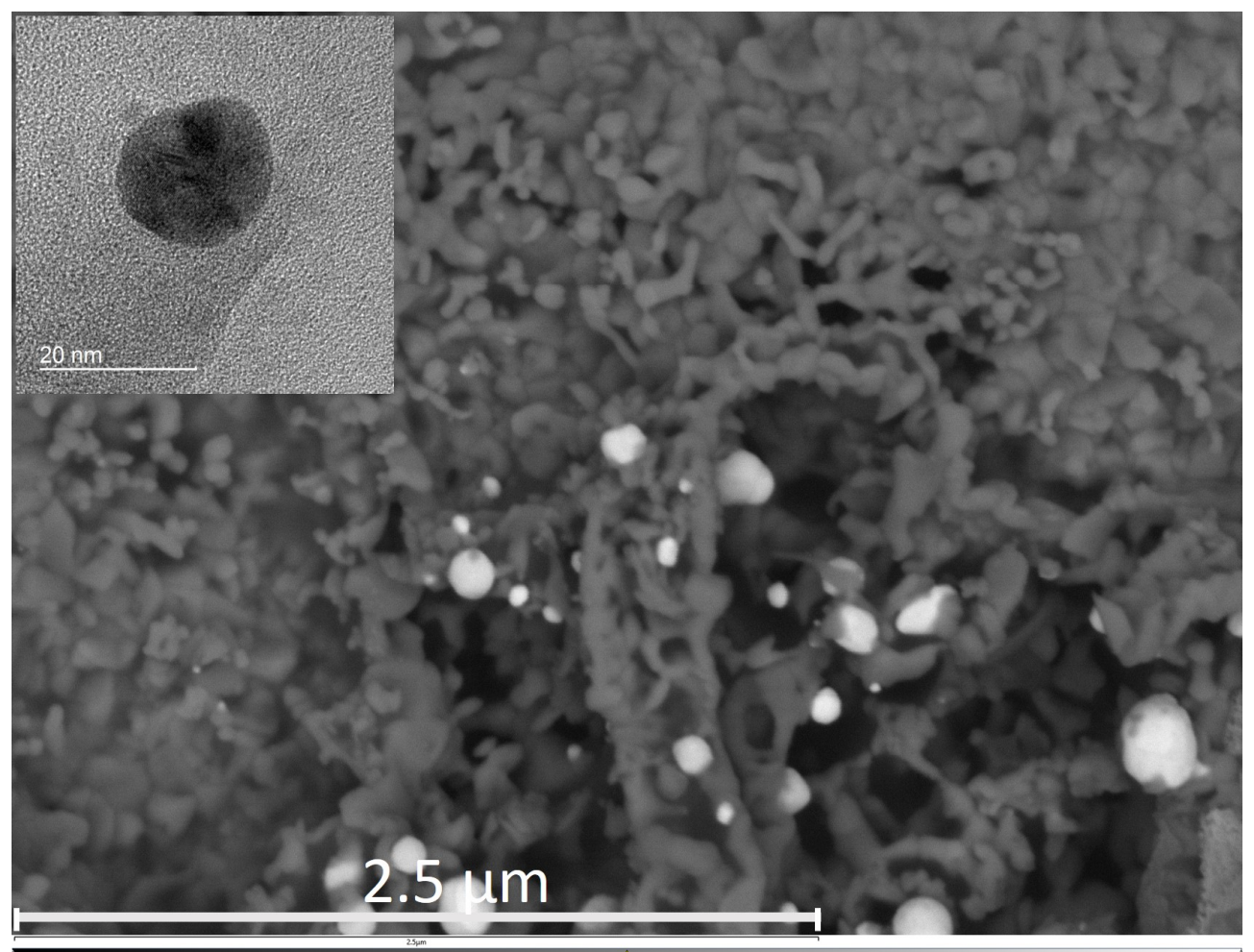

Figure 3. SEM image of the investigated sensor surface area containing Au nanoparticles. The insert shows a TEM image of a single nanoparticle.

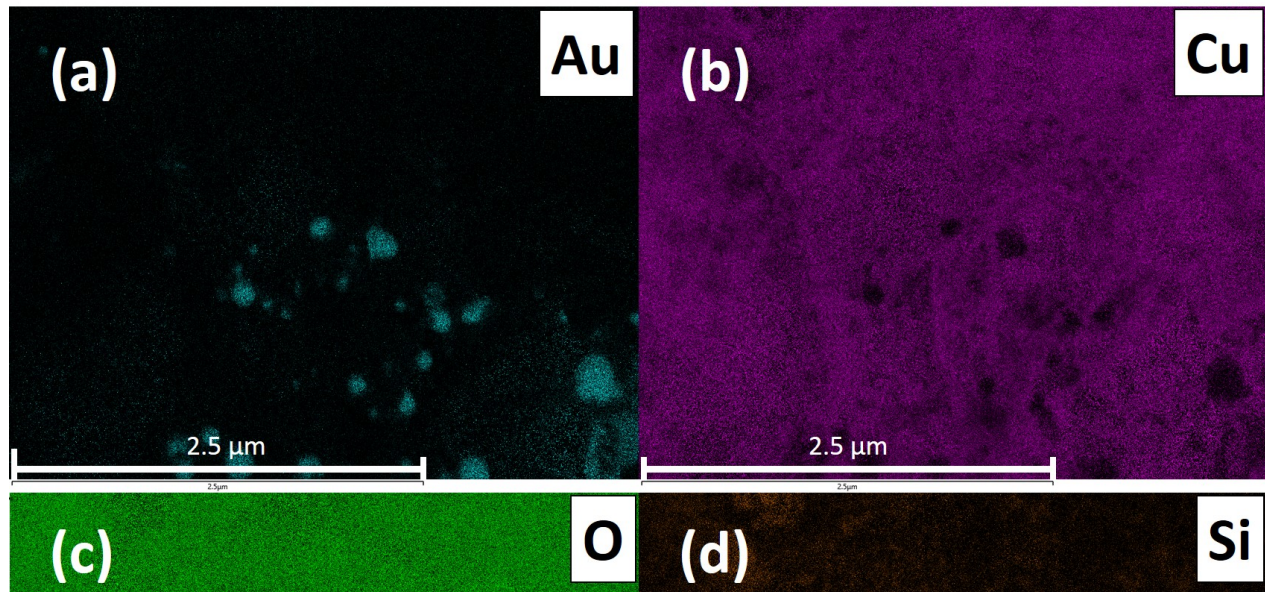

Figure 4. Elemental mapping of a $4 \mu \mathrm{m} \times 4 \mu \mathrm{m}$ section on the copper oxide surface with $5 \mathrm{keV}$ (primary beam energy). (a) Au elemental map, (b) Cu elemental map, (c) O elemental map and (d) $\mathrm{Si}$ elemental map. 


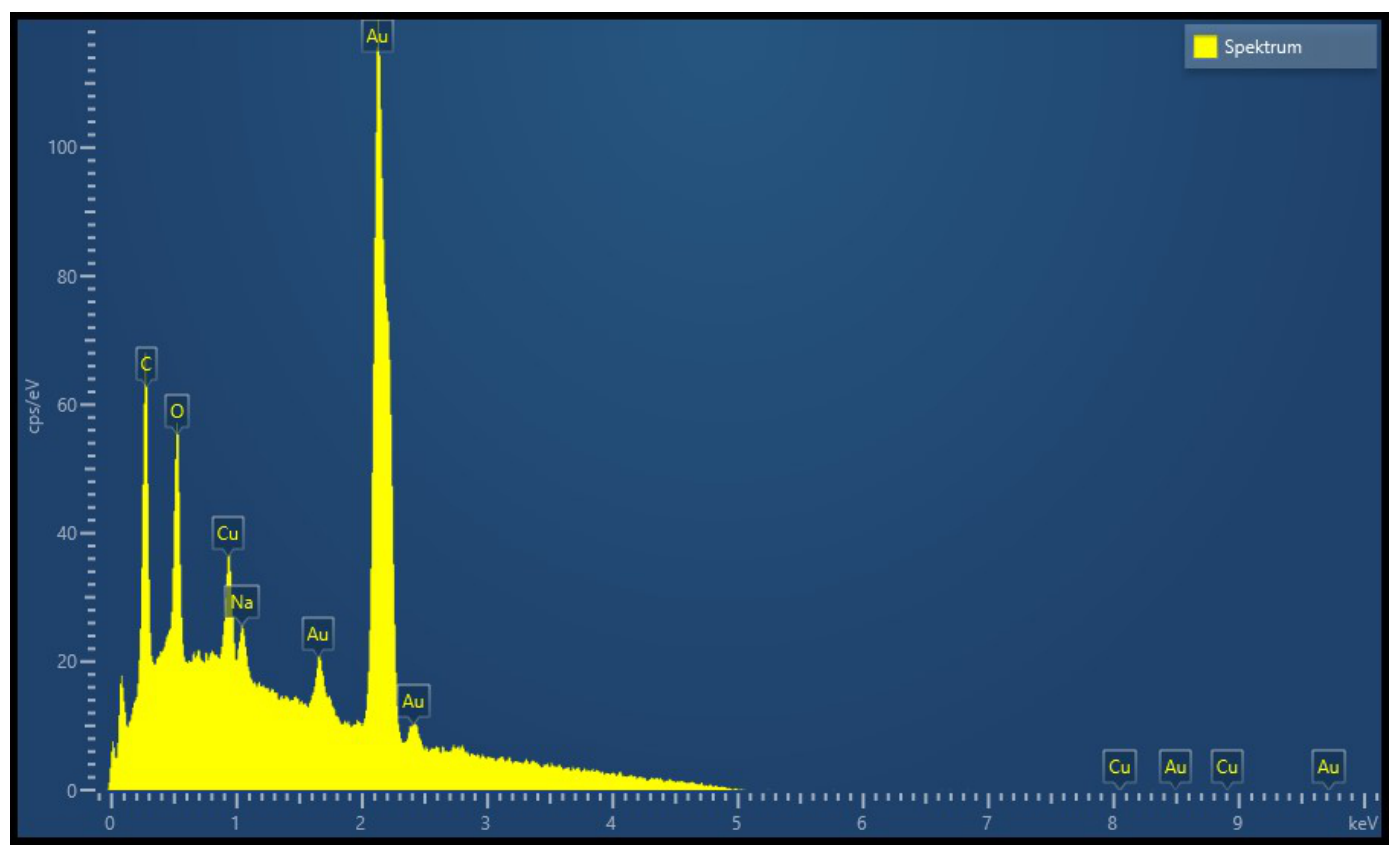

Figure 5. EDX spectrum of a single nanoparticle on the copper oxide surface at $5 \mathrm{keV}$.

\subsection{Carbon Dioxide Measurements of a Pristine and Functionalized Gas Sensor}

The $\mathrm{CO}_{2}$ measurements were performed in the GMS (see Section 2.5). The evaluation of the gas sensors' performance towards $\mathrm{CO}_{2}$ was done following this measurement plan: the gas sensor was operated at three different temperatures $\left(300{ }^{\circ} \mathrm{C}, 350^{\circ} \mathrm{C}, 400^{\circ} \mathrm{C}\right)$ and for each operating temperature three $\mathrm{rH}$ levels $(25 \%, 50 \%, 75 \%)$ were set. Within each $\mathrm{rH}$ level a series of $\mathrm{CO}_{2}$ gas pulses (single pulse duration: $5 \mathrm{~min}$ ) with various concentrations ( 250 ppm, 500 ppm, 1000 ppm, 1500 ppm and 2000 ppm) were applied to meet the general demands of indoor air quality monitoring. Figure 6 shows the sensor resistances of the pristine (not functionalized with nanoparticles) and the Au-NPs functionalized $\mathrm{CuO}$ sensors responding to different concentrations of $\mathrm{CO}_{2}$ at $300{ }^{\circ} \mathrm{C}$ operation temperature. Herein, it can be seen that the base resistance of the functionalized sensor decreases by a factor of 2 compared to the pristine sensor. The pristine $\mathrm{CuO}$ sensor exhibits a small response to $\mathrm{CO}_{2}$ (maximum $28 \%$ ), which decreases with increasing $\mathrm{rH}$ level. The response of the functionalized $\mathrm{CuO}$ sensor is 13 times higher and reaches a maximum of $365 \%$. The response increases linearly with the $\mathrm{CO}_{2}$ concentration. To the best of our knowledge this is one of the highest reported sensitivities of a conductometric $\mathrm{CO}_{2}$ sensor. For clear comparison the gas sensor performance of the pristine and Au-NPs functionalized $\mathrm{CuO}$ sensors to $\mathrm{a}_{2}$ concentration of $2000 \mathrm{ppm}$ are shown in Figures 7 and 8, respectively, for three different operation temperatures $\left(300{ }^{\circ} \mathrm{C}, 350{ }^{\circ} \mathrm{C}, 400{ }^{\circ} \mathrm{C}\right)$ and three different $\mathrm{rH}$ levels $(25 \%, 50 \%, 75 \%)$. The sensitivities are normalized in accordance with Equation (1).

Figure 7 depicts the $\mathrm{CO}_{2}$ gas measurement of a pristine $\mathrm{CuO}$ gas sensor towards a single $\mathrm{CO}_{2}$ gas pulse of $2000 \mathrm{ppm}$. In this figure the gas sensor response for all three sensor operation temperatures is shown for constant relative humidity levels of (a) $25 \%$, (b) $50 \%$ and (c) $75 \%$. Figure $7 \mathrm{~d}$ depicts the $\mathrm{CO}_{2}$ gas pulse of $2000 \mathrm{ppm}$. The sensitivity of the pristine $\mathrm{CuO}$ gas sensor reaches a maximum of $32 \%$ at an operation temperature of $350^{\circ} \mathrm{C}$ and a rH-level of $50 \%$.

Figure 8 shows the sensitivity of the Au-NPs functionalized $\mathrm{CuO}$ gas sensor. Please note that the sensitivity scale of Figure 8 is expanded by a factor of ten as compared to the scale of Figure 7 . The functionalized $\mathrm{CuO}$ gas sensor reaches a maximum of $365 \%$ at an operation temperature of $300{ }^{\circ} \mathrm{C}$ and at a rH-level of $50 \%$. The maximum sensitivity is a factor of 11 higher than that of the pristine sensor at its optimal, operation temperature of $350^{\circ} \mathrm{C}$. The response of the Au-NPs functionalized $\mathrm{CuO}$ sensor decreases with increasing temperature $\left(350{ }^{\circ} \mathrm{C}\right)$ and drops drastically at $400{ }^{\circ} \mathrm{C}$ operation temperature. 


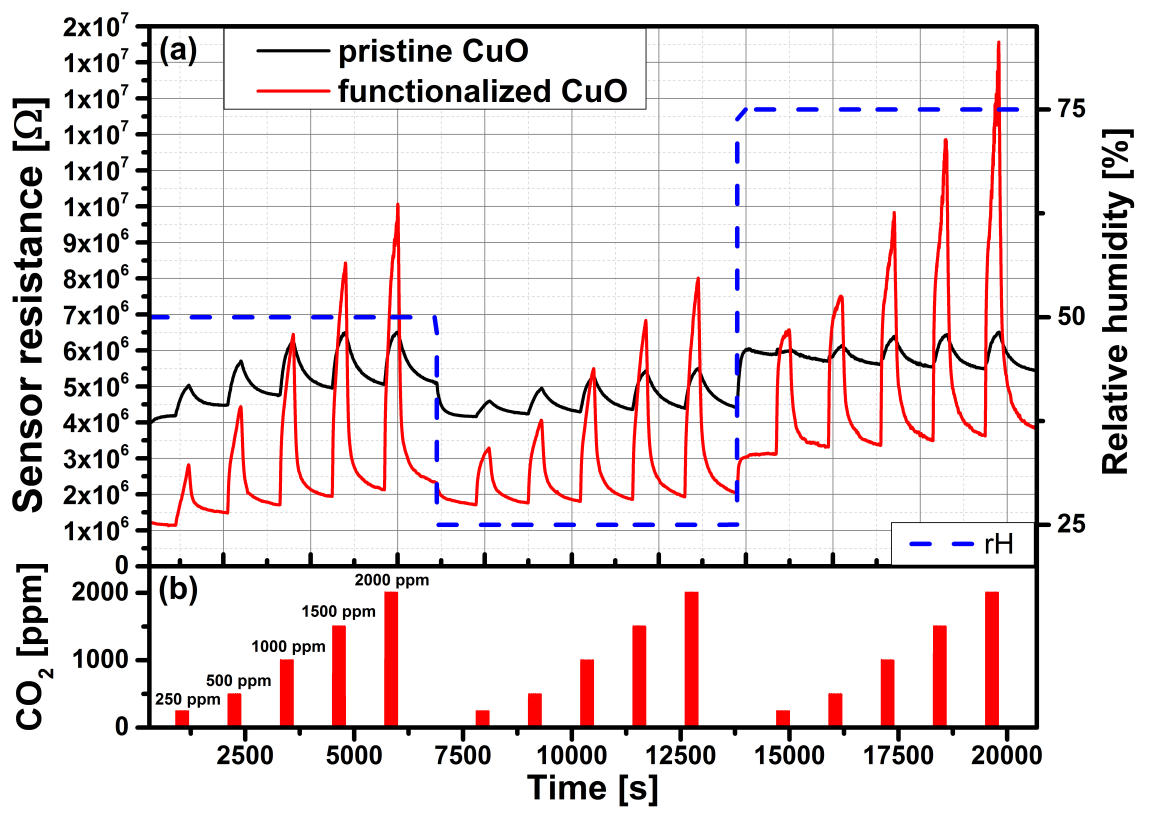

Figure 6. (a) Carbon dioxide measurement of the pristine and functionalized $\mathrm{CuO}$ gas sensors at an operation temperature of $300{ }^{\circ} \mathrm{C}$ and $\mathrm{rH}$ levels of $25 \%, 50 \%$ and $75 \%$. (b) $\mathrm{CO}_{2}$ gas pulses: $250 \mathrm{ppm}$, 500 ppm, 100 ppm, 1500 ppm and 2000 ppm.

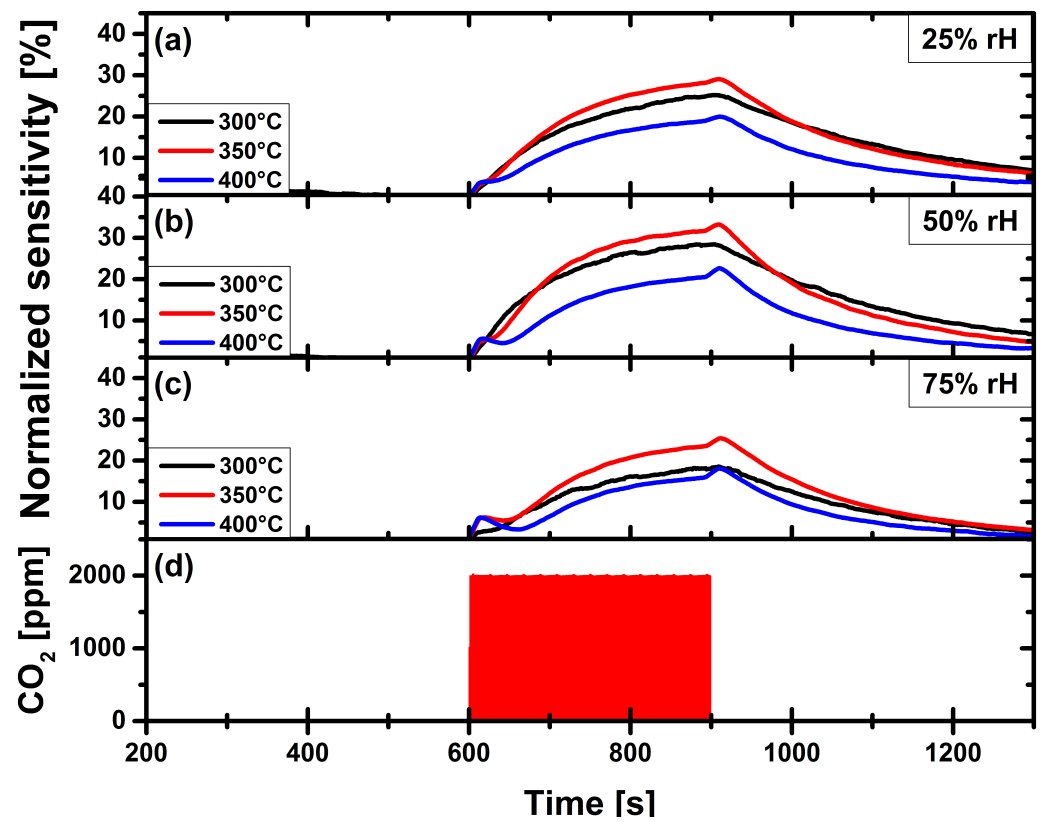

Figure 7. Carbon dioxide measurement of pristine $\mathrm{CuO}$ gas sensor, at operation temperatures $300{ }^{\circ} \mathrm{C}$, $350{ }^{\circ} \mathrm{C}$ and $400{ }^{\circ} \mathrm{C}$, at constant relative humidity levels of: (a) $25 \%$. (b) $50 \%$. (c) $75 \%$. (d) Applied gas pulse of $2000 \mathrm{ppm} \mathrm{CO}_{2}$.

In Figure 9 the maximum sensitivities of the pristine sensor and the Au-NPs functionalized sensor to a $\mathrm{CO}_{2}$ concentration of 2000 ppm are compared for the different relative humidity levels $(25 \%$, $50 \%, 75 \%$ ) at the same operation temperature of $300{ }^{\circ} \mathrm{C}$. The functionalized sensor has a maximum sensitivity of $365 \%$ at $50 \% \mathrm{rH}$, which decreases down to $283 \%$ at $75 \% \mathrm{rH}$. Its average response time is $4.3 \mathrm{~min}$ with an average recovery time of $4.4 \mathrm{~min}$. The pristine sensor has a maximum sensitivity of $28 \%$ at $50 \% \mathrm{rH}$, which decreases down to $18 \%$ at $75 \% \mathrm{rH}$. The average response time for the pristine sensor 
is $3.7 \mathrm{~min}$, whereas the its average recovery time is $11.1 \mathrm{~min}$. At the same operation temperature of $300{ }^{\circ} \mathrm{C}$ the sensitivity of the Au-NPs functionalized sensor is even increased by a factor of 13 compared to the pristine sensors' sensitivity. While both types of sensors exhibit a certain cross-sensitivity to water, this sensitivity drop is much less in the case of the functionalized sensor. Functionalization with Au-NPs thus not only increases the sensitivity, but also decreases cross-sensitivity to humidity.

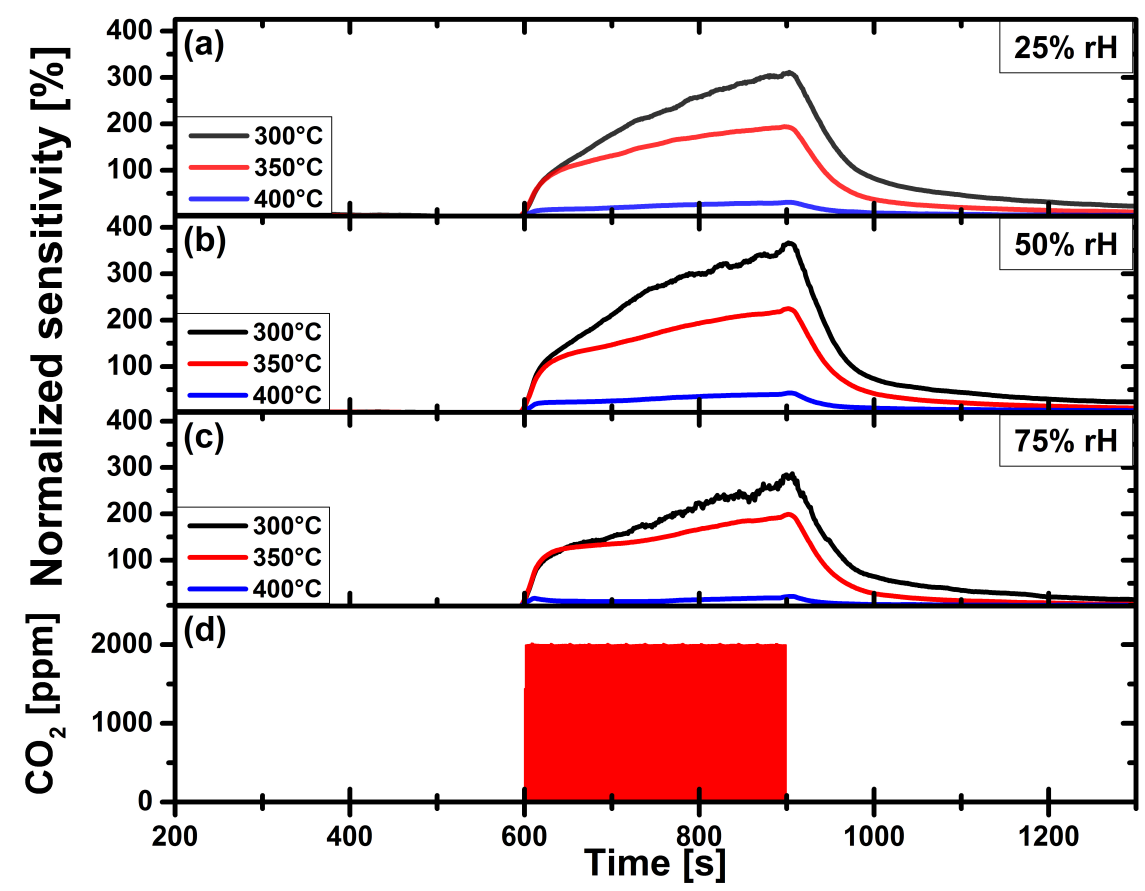

Figure 8. Carbon dioxide measurement of gold nanoparticles functionalized $\mathrm{CuO}$ gas sensor, at operation temperatures $300{ }^{\circ} \mathrm{C}, 350^{\circ} \mathrm{C}$ and $400{ }^{\circ} \mathrm{C}$, at constant relative humidity levels of: (a) $25 \%$. (b) $50 \%$. (c) $75 \%$. (d) Applied gas pulse of 2000 ppm $\mathrm{CO}_{2}$.

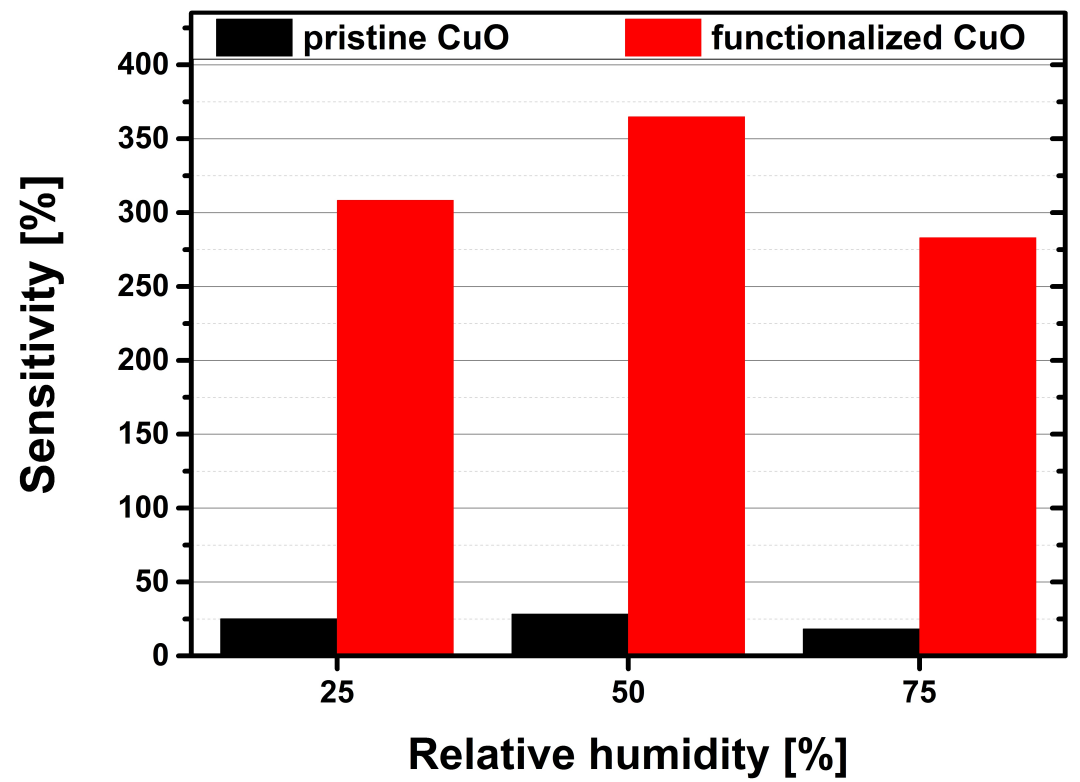

Figure 9. Comparison of the pristine (black bars) and the Au-NPs functionalized (red bars) gas sensors sensitivities towards a $2000 \mathrm{ppm} \mathrm{CO}_{2}$ gas pulse at relative humidity levels of $25 \%, 50 \%$ and $75 \%$ at an operation temperature of $300^{\circ} \mathrm{C}$. 


\subsection{Carbon Monoxide Measurements}

Cross selectivity is an important issue for chemical sensors. Our sensor developments are focused on indoor air quality monitoring, where detection of carbon monoxide (CO) is important for safety reasons. $\mathrm{CO}$ is a color- and odorless gas, which is highly toxic. Incomplete combustion of natural gas in gas appliances, such as boilers, gas fires, or gas cookers can lead to people being exposed to $\mathrm{CO}$ in their homes or at work place. Prolonged exposure to $\mathrm{CO}$ in case of a defect heating system, for example, can eventually be fatal. The maximum permitted work place concentration value for $\mathrm{CO}$ is 30 ppm [19] in Germany. Thus, the sensitivity of the Au-NPs functionalized CuO-based sensors has been also evaluated towards $\mathrm{CO}$. Figure 10 shows the sensitivity of the Au-NPs functionalized $\mathrm{CuO}$-based gas sensor towards $\mathrm{CO}_{2}$ and $\mathrm{CO}$. The $\mathrm{CuO}$-based sensors show a response of less than $5 \%$ at $\mathrm{CO}$ concentrations around $20 \mathrm{ppm}$. Thus, to achieve a relevant response, the concentration of $\mathrm{CO}$ has been increased up to $200 \mathrm{ppm}$, which is compared with the response to a $\mathrm{CO}_{2}$ concentration of $2000 \mathrm{ppm}$. The sensor temperature is set to $300{ }^{\circ} \mathrm{C}$, since this is the optimum operation temperature for both test gases. Furthermore, the sensitivities have been evaluated for three different relative humidity levels $(25 \%, 50 \%, 75 \%)$.

The sensitivity of the gas sensor towards $\mathrm{CO}$ reaches its maximum of $86 \%$ at $50 \% \mathrm{rH}$. At $75 \% \mathrm{rH}$ the sensitivity to CO decreases to $56 \%$. The average response time for the CO measurement is $3 \mathrm{~min}$, whereas the average recovery time is $10 \mathrm{~min}$. The direct comparison of the Au-NPs functionalized sensors' sensitivity to the maximum concentrations of $\mathrm{CO}_{2}$ and of $\mathrm{CO}$ at $50 \% \mathrm{rH}$ shows that the $\mathrm{CO}_{2}$ sensitivity is roughly 4 times higher than the $\mathrm{CO}$ sensitivity. Figure 10 clearly shows that the CuO-based sensor exhibits a much higher sensitivity towards $\mathrm{CO}_{2}$ which is enough to discriminate between the two different target gases.

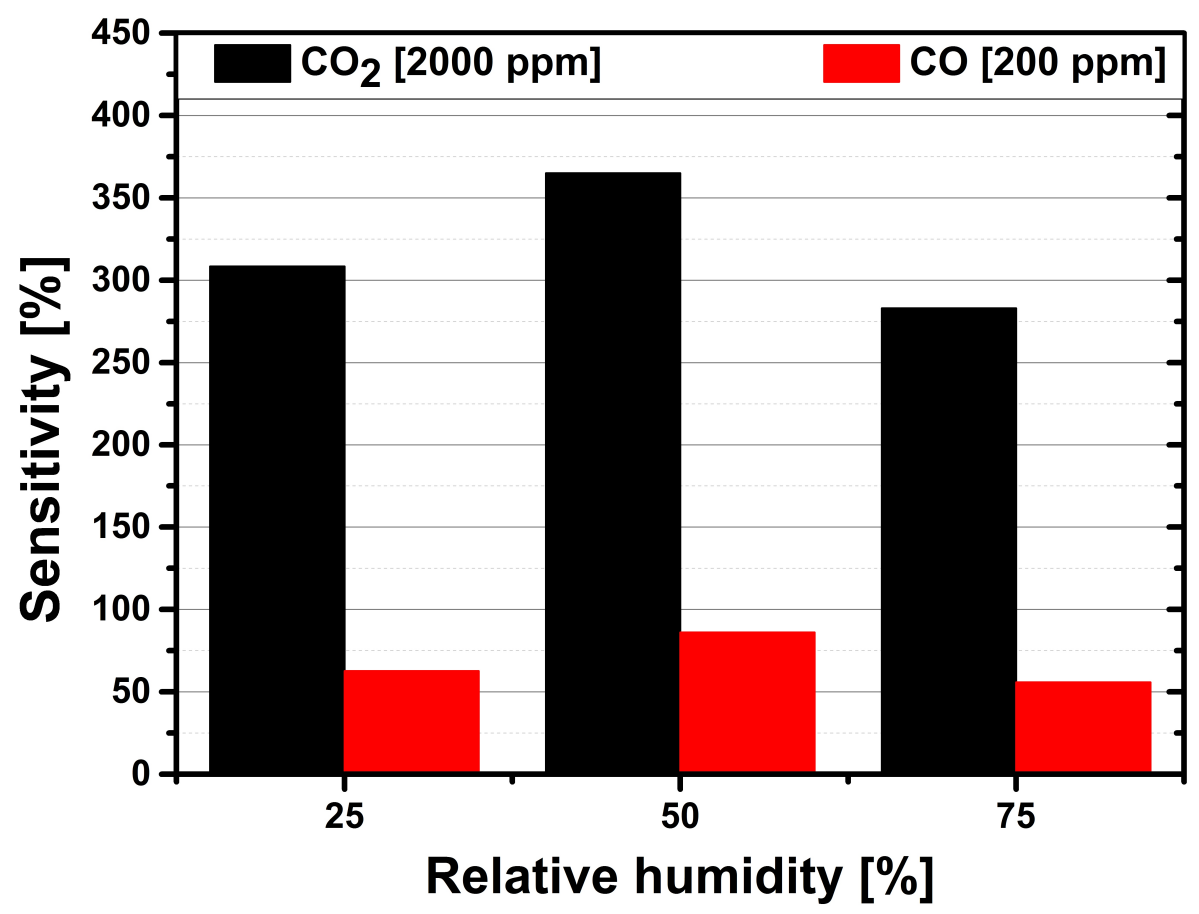

Figure 10. Comparison of the Au-NPs functionalized gas sensors sensitivities towards a $2000 \mathrm{ppm}$ $\mathrm{CO}_{2}$ gas pulse (black bars) and a $200 \mathrm{ppm} \mathrm{CO}$ gas pulse (red bars) at relative humidity levels of $25 \%$, $50 \%$ and $75 \%$ at an operation temperature of $300{ }^{\circ} \mathrm{C}$. 


\section{Discussion and Conclusions}

The $\mathrm{CuO}$ films used within this work are formed during an in situ thermal oxidation process [20]. It is well established that metallic $\mathrm{Cu}$ predominately oxidizes into cuprous oxide $\left(\mathrm{Cu}_{2} \mathrm{O}\right)$ or cupric oxide $(\mathrm{CuO})$. As proven by Raman spectroscopy, in case of our sensors the thermal oxidation resulted in $\mathrm{CuO}$. According to Chen et al. [21] copper oxidizes by forming a multi-layer system of metallic $\mathrm{Cu}, \mathrm{Cu}_{2} \mathrm{O}$ and $\mathrm{CuO}$. $\mathrm{Xu}$ et al. [22], who investigated the thermal oxidation of $\mathrm{Cu}$ foils, found that oxidation temperatures of $400{ }^{\circ} \mathrm{C}$ and higher would result in the formation of $\mathrm{CuO}$ nanowires. In our case, however, only a few $\mathrm{CuO}-\mathrm{NW}$ s have been found on the thermally oxidized $\mathrm{Cu}$ structures. The employed $\mathrm{Cu}$ structures have a smaller lateral dimension and thickness, and thus much less volume than a bulk material. Furthermore, the Cu-layers have been deposited by thermal evaporation method. Both specific features_-small Cu volume and evaporation method-could lead to a deviation from $\mathrm{Xu}$ 's findings. The authors presume the gaps between the $\mathrm{Cu}$ stripes provide additionally lateral room for the thermal copper oxide to expand. Thereby, the built-up of strain or stress in the Cu structure, which are strong driving forces for the growth of $\mathrm{CuO}-\mathrm{NW}$ during oxidation, is to a large extent avoided. As a result, the formation of the $\mathrm{CuO}$ nanowires could be inhibited.

The SEM investigation show (Figure 2a) that the gaps between the copper structures are bridged by the expanding $\mathrm{CuO}$. We conclude that the thermal oxidation process results first in a multi-layer of $\mathrm{Cu}, \mathrm{Cu}_{2} \mathrm{O}$ and $\mathrm{CuO}$ [21], which is subsequently fully converted to $\mathrm{CuO}$ during the six hours oxidation. This is in accordance with the work of Adilov et al. [23], who found that $\mathrm{Cu}_{2} \mathrm{O}$ films heated to a temperature of $400{ }^{\circ} \mathrm{C}$ and above would transform into $\mathrm{CuO}$. This assumption is fully supported by Raman spectroscopy measurement, where no peaks for $\mathrm{Cu}$ - and $\mathrm{Cu}_{2} \mathrm{O}$-phases have been found on our sensing films.

It has already been reported in literature that $\mathrm{CuO}$ is sensitive to carbon dioxide [16,24]. The results in Figure 7 show that the maximum sensitivity of our pristine $\mathrm{CuO}$ sensor exposed to a $\mathrm{CO}_{2}$ concentration of $2000 \mathrm{ppm}$ at $50 \% \mathrm{rH}$ and an operation temperature of $350{ }^{\circ} \mathrm{C}$ is $35 \%$. This supports findings in literature and can be compared to $\mathrm{CuO}$-based sensors reported by Abdelmounaim et al. [24] and Ishihara et al. [25].

A potential surface reaction explaining the interaction between the target gas $\mathrm{CO}_{2}$ and the sensing material CuO (NPs) has been described by Tanvir et al. [16]. A key reactant of this reaction is humidity. The authors of [16] presume that the $\mathrm{CuO}-\mathrm{NPs}^{\prime}$ surface reacts with $\mathrm{CO}_{2}$ and $\mathrm{H}_{2} \mathrm{O}$ forming either malachite or azurite, since these reactions are thermodynamically more favorable than the formation of copper carbonate $\left(\mathrm{CuCO}_{3}\right)$. Equations (3) and (4) display the formation equations of these two hydroxycarbonates. Furthermore, Tanvir et al. [16] presume that $\mathrm{CO}_{2}$ can either be available on the surface in its gaseous phase or solvated in water. Table 1 shows the Gibbs free energy for the formation of malachite and azurite at 400 ppm CO 2 at 298.15 K. Equations (A1), (A2) and (A3) and literature values (Table A4) used for the calculations of the values in Table 1 can be found in the appendix. Since malachite and azurite are both insulators the formation of those compounds on the sensor surface would result in a resistance increase. This sensing mechanism deviates from the established ionosorption model, where adsorbed ionic oxygen species on the sensor surface interact with the test gas resulting in resistance change of the sensor.

$$
\begin{gathered}
2 \mathrm{CuO}_{(s)}+\mathrm{CO}_{2(a q)}+\mathrm{H}_{2} \mathrm{O}_{(l)} \rightleftharpoons \mathrm{Cu}_{2}(\mathrm{OH})_{2} \mathrm{CO}_{3(s)} \\
3 \mathrm{CuO}_{(s)}+2 \mathrm{CO}_{2(a q)}+\mathrm{H}_{2} \mathrm{O}_{(l)} \rightleftharpoons \mathrm{Cu}_{3}(\mathrm{OH})_{2}\left(\mathrm{CO}_{3}\right)_{2(s)}
\end{gathered}
$$


Table 1. Gibbs free energy of the malachite and azurite reaction (Equations (3) and (4)) at $298.15 \mathrm{~K}$ at 400 ppm of $\mathrm{CO}_{2}$.

\begin{tabular}{ccc}
\hline Hydroxycarbonate & $\mathrm{CO}_{2}[\mathbf{p p m}]$ & $\boldsymbol{\Delta}_{\boldsymbol{R}} \mathrm{G}\left[\frac{\mathrm{kJ}}{\mathrm{mol}}\right]$ at $298.15 \mathrm{~K}$ \\
\hline malachite $\left[\mathrm{Cu}_{2}(\mathrm{OH})_{2} \mathrm{CO}_{3(s)}\right]$ & 400 & -8.3 \\
azurite $\left[\mathrm{Cu}_{3}(\mathrm{OH})_{2}\left(\mathrm{CO}_{3}\right)_{2(s)}\right]$ & 400 & -8.2 \\
\hline
\end{tabular}

The decrease in sensor sensitivity at temperatures exceeding the optimal operation temperature of $300{ }^{\circ} \mathrm{C}$ can be connected to the formation of malachite or azurite too. Seguin [26] investigated the dissociation of malachite and azurite by DTA measurements. Seguin found that the malachite dissociates in a temperature window of $310^{\circ} \mathrm{C}$ to $420^{\circ} \mathrm{C}$, whereas azurite dissociates between $290{ }^{\circ} \mathrm{C}$ to $395^{\circ} \mathrm{C}$. Therefore, the authors presume that malachite is mainly responsible for the sensing mechanism at the optimal operation temperature. Furthermore, the dissociation of malachite and azurite at these temperatures explains the decrease in sensitivity at the investigated operation temperatures of $350{ }^{\circ} \mathrm{C}$ and $400{ }^{\circ} \mathrm{C}$.

The dramatic increase of the sensitivity to $\mathrm{CO}_{2}$ has been achieved by functionalizing the pristine $\mathrm{CuO}$ film with Au-NPs. According to Korotcenkov [27] nanoparticles deposited onto a MOx surface in general change the sensitivity of a metal oxide gas sensor either by chemical sensitization or electronic sensitization. The authors presume that the interface of metal oxide and gold nanoparticles provide additional active cites for the adsorption of $\mathrm{CO}_{2}$. A similar process was reported by Yang et al. [28], where the base material was a $\mathrm{CeO}_{x} / \mathrm{TiO}_{2}$ substrate on which Au nanoparticles were deposited. As a result, the adsorption of $\mathrm{CO}_{2}$ increased. In our case, the increased $\mathrm{CO}_{2}$ adsorption could lead to a rise in malachite formation, thereby increasing the sensors' sensitivity. However, at the moment we do not understand this interaction mechanism yet. We cannot exclude chemical surface reactions such as diffusion of $\mathrm{Au}$ into the $\mathrm{CuO}$ and resulting alloy of $\mathrm{Au}-\mathrm{CuO}$ hybrid NPs or similar effects, which might arise due to the high operation temperature up to $400^{\circ} \mathrm{C}$. Detailed analysis of the Au-NPs functionalized $\mathrm{CuO}$ surface with respect to potentially new alloys or phases are presently under investigation in order to clarify the surface reaction process for the Au-NPs functionalized $\mathrm{CuO}$ film.

The lifetime of the $\mathrm{CO}_{2}$ sensor has been tested over more than 2 weeks in DC-operation and a degradation of the sensor performance has been observed, which the authors mainly attribute to structural changes of the functionalization. As is obvious from Figure 3, the Au nanoparticles seem to agglomerate over time, which might be responsible for a reduced response. Another issue is the adhesion of the $\mathrm{CuO}$-layer on the Si-substrate. Although the chosen patterns ( $\mathrm{Cu}$ stripes) release part of the stress/strain during thermal oxidation, reliable adhesion is still a problem. Optimization of the process technology steps (variation of gap width between $\mathrm{Cu}$ stripes, $\mathrm{Cu}$-thickness etc.) is in progress. Concerning repeatability, the process technology used in this work to functionalize the $\mathrm{CuO}$ surface with the Au nanoparticles is drop-coating. Since this method has limits concerning reproducibility, more precise technologies for deposition such as ink-jet printing will be employed in the future to ensure repeatable Au-coverage.

The issue of cross-sensitivity is investigated by the evaluation of the Au-NPs functionalized sensors' sensitivity towards carbon monoxide. Figure 10 clearly shows that the sensor exhibits a higher sensitivity towards $\mathrm{CO}_{2}$. Although the maximum concentrations, which are compared in Figure 10 are not equivalent, this comparison reflects practical requirements for indoor air quality monitoring. $\mathrm{CO}_{2}$ concentration can easily exceed 2000 ppm in closed rooms, which can be detected by the CuO-based sensor even in case of extremely high CO concentration of $200 \mathrm{ppm}$. For detection of CO concentrations well below $100 \mathrm{ppm} \mathrm{SnO} 2$-based gas sensors can be employed. A combination of the $\mathrm{CuO}$-based $\mathrm{CO}_{2}$ sensor and a $\mathrm{SnO}_{2}$-based sensor would thus be a proper choice for air quality as well as safety issues. In case of a HVAC system monitored by such a sensor combination, the HVAC would immediately blow in fresh air. 
In conclusion, it has been shown that $\mathrm{CuO}$ formed by in situ thermal oxidation and functionalized with gold nanoparticles exhibits a high sensitivity towards $\mathrm{CO}_{2}$. Direct comparison of the pristine and $\mathrm{Au}-\mathrm{NPs}$ functionalized $\mathrm{CuO}$ sensor shows a sensitivity increase by a factor 13 (comparison: $\mathrm{CO}_{2}$ $2000 \mathrm{ppm}, \mathrm{rH} 50 \%$, operation temperature $300{ }^{\circ} \mathrm{C}$ ). Compared to the sensitivity values of various MOx gas sensors found in literature (see Table A1), the gas sensor introduced in this work exhibits one of the highest sensitivities towards $\mathrm{CO}_{2}$, at lower temperatures. The process flow of our Au-NPs functionalized $\mathrm{CuO}$ gas sensor enables integration on CMOS-based microhotplates.

\section{Patents}

The fabrication procedure and the $\mathrm{CO}_{2}$ sensor with the specific sensing material are subject-matter of Austrian patent application no. A 50377/2018 filed on May 4, 2018.

Author Contributions: The concept of the presented work has been elaborated by R.W.-T. and A.K.; J.S.N. and O.T. provided the Au-NPs for the sensor fabrication process; the gas sensors were fabricated by R.W.-T.; the gas measurements were conducted by R.W.-T., F.S.-L. and B.Z.T.; the Raman measurement was done by M.D.; the evaluation of the measurements was done by R.W.-T., F.S.-L., M.D. and S.D.; all authors contributed to the writing process.

Funding: This work was funded in part by the Sevenths Framework Programme for Research and Technological Development of the European Union as part of the MSP - Multi-Sensor Platform for Smart Building Management [No. 611887] and the ECSEL project IOSense [GA. No. 692480, FFG No. 6054961].

Acknowledgments: The authors want to thank Günther Maier for valuable discussion during the writing process. Furthermore, the authors want to thank Bernhard Sartory for the SEM investigations.

Conflicts of Interest: The authors declare no conflict of interest.

\section{Abbreviations}

The following abbreviations are used in this manuscript:

$\begin{array}{ll}\mathrm{MOx} & \text { Metal oxide } \\ \mathrm{CO}_{2} & \text { Carbon dioxide } \\ \mathrm{CMOS} & \text { Complementary metal oxide semiconductor } \\ \mathrm{CuO} & \text { Cupric oxide } \\ \mathrm{Cu}_{2} \mathrm{O} & \text { Cuprous oxide } \\ \mathrm{HVAC} & \text { Heating, ventilation and air conditioning } \\ \mathrm{rH} & \text { Relative humidity } \\ \text { ppm } & \text { Parts per million } \\ \mathrm{Au}-\mathrm{NP} & \text { Gold nanoparticles } \\ \text { GMS } & \text { Gas measurement set-up }\end{array}$

\section{Appendix A. Supplementary Information}

Appendix A.1. Metal Oxide-Based Carbon Dioxide Gas Sensors

Table A1. $\mathrm{CO}_{2}$ responses of various metal oxide materials reported in literature.

\begin{tabular}{ccccc}
\hline Material & T $_{\text {operation }}\left[{ }^{\circ} \mathrm{C}\right]$ & Response $\frac{R_{\text {gas }}}{R_{\text {air }}}$ & $\mathbf{C O}_{2}[\mathbf{p p m}]$ & Reference \\
\hline $\mathrm{La}_{2} \mathrm{O}_{3} / \mathrm{SnO}_{2}$ & 400 & 3.6 & 2000 & {$[29]$} \\
$\mathrm{LaOCl}$ & 260 & 3.4 & 2000 & {$[30]$} \\
$\mathrm{LaOCl}$-functionalized $\mathrm{SnO}_{2}$ nanowires & 400 & 5.6 & 2000 & {$[31]$} \\
$\mathrm{Au}-\mathrm{NPs}$ functionalized $\mathrm{CuO}$ & 300 & 4.7 & 2000 & this work \\
\hline
\end{tabular}


Appendix A.2. Photolithography

Table A2. Process parameters for the fabrication of gold electrodes.

\begin{tabular}{|c|c|}
\hline \multicolumn{2}{|c|}{ (1) Photolithography } \\
\hline Positive photoresist & AZ ${ }^{\circledR}$ MIR701 (Microchemicals GmbH) \\
\hline Spin-coating speed [rpm] & 4000 \\
\hline Spin-coating duration [s] & 35 \\
\hline Annealing temperature $\left[{ }^{\circ} \mathrm{C}\right]$ & 90 \\
\hline Annealing duration [s] & 60 \\
\hline Developer & AZ ${ }^{\circledR}$ MIF726 (Microchemicals GmbH) \\
\hline Development duration [s] & 30 \\
\hline Stopper & deionized water \\
\hline Stopper duration [s] & 120 \\
\hline \multicolumn{2}{|c|}{ (2) Thermal Evaporation } \\
\hline Adhesion layer & titanium \\
\hline Adhesion layer thickness [nm] & 5 \\
\hline Primary layer & gold \\
\hline Primary layer thickness [nm] & 200 \\
\hline \multicolumn{2}{|c|}{ (3) Lift-Off } \\
\hline Solvent & acetone \\
\hline Duration $[\mathrm{h}]$ & 12 \\
\hline
\end{tabular}

Appendix A.3. Electron Beam Lithography

Table A3. Process parameters for the fabrication of the $\mathrm{CuO}$ thin film functionalized with Au nanoparticles.

\begin{tabular}{|c|c|}
\hline \multicolumn{2}{|c|}{ (1) Electron Beam Lithography } \\
\hline Positive PMMA resist & AR-P 672.08 (ALLRESIST GmbH) \\
\hline Spin-coating speed [rpm] & 2000 \\
\hline Spin-coating duration [s] & 60 \\
\hline Annealing temperature $\left[{ }^{\circ} \mathrm{C}\right]$ & 180 \\
\hline Annealing duration $[\mathrm{s}]$ & 300 \\
\hline Developer & AR600-55 (ALLRESIST GmbH) \\
\hline Development duration [s] & 15 \\
\hline Stopper & AR600-60 (ALLRESIST GmbH) \\
\hline Stopper duration $[\mathrm{s}]$ & 60 \\
\hline \multicolumn{2}{|c|}{ (2) Thermal Evaporation } \\
\hline Adhesion layer & titanium \\
\hline Adhesion layer thickness [nm] & 5 \\
\hline Primary layer & copper \\
\hline Primary layer thickness [nm] & 500 \\
\hline \multicolumn{2}{|c|}{ (3) Lift-Off } \\
\hline Solvent & acetone \\
\hline Duration $[\mathrm{h}]$ & 4 \\
\hline \multicolumn{2}{|c|}{ (4) Thermal Oxidation } \\
\hline Oxidation temperature $\left[{ }^{\circ} \mathrm{C}\right]$ & 400 \\
\hline Oxidation duration $[\mathrm{h}]$ & 6 \\
\hline Relative humidity [\%] & 50 \\
\hline \multicolumn{2}{|c|}{ (5) Au Nanoparticles Depositon } \\
\hline Deposition volume $[\mu \mathrm{L}]$ & 40 \\
\hline Deposition temperature $\left[{ }^{\circ} \mathrm{C}\right]$ & 85 \\
\hline
\end{tabular}


Appendix A.4. Equations for Gibbs Free Energy Calculation

The equations used for calculations were taken form the work of Tanvir et al. [16].

1. Standard Gibbs free energy for the formation of a compound:

$$
\Delta_{R} G^{0}=\sum \Delta_{f} G_{\text {product }}^{0}-\sum \Delta_{f} G_{\text {educt }}^{0}
$$

$\Delta_{R} G^{0}$ : Change of the standard Gibbs free energy of the examined chemical reaction at standard conditions. Standard conditions refer to a temperature of $298.15 \mathrm{~K}$ and a pressure of 1 bar.

$\sum \Delta_{f} G_{\text {product }}^{0}$ : Sum over all standard Gibbs free energies of the products.

$\sum \Delta_{f} G_{\text {educt }}^{0}$ : Sum over all standard Gibbs free energies of the educts.

2. Gibbs free energy at varying pressures (malachite):

$$
\Delta_{R} G=\Delta_{R} G^{0}+R T \ln \left(p_{\mathrm{CO}_{2}}\right)^{-1}
$$

3. Gibbs free energy at varying pressures (azurite):

$$
\Delta_{R} G=\Delta_{R} G^{0}+R T \ln \left(p_{\mathrm{CO}_{2}}\right)^{-2}
$$

$\Delta_{R} G$ : Change of Gibbs free energy of formation at a partial pressure varying from standard conditions.

$\Delta_{R} G^{0}$ : Change of the standard Gibbs free energy of the examined chemical reaction at standard conditions. Standard conditions refer to a temperature of $298.15 \mathrm{~K}$ and a pressure of $1 \mathrm{bar}$.

R: Gas constant. $\mathrm{R}=8.314 \frac{\mathrm{I}}{\mathrm{K} \cdot \mathrm{mol}}$

T: Temperature.

$\mathrm{p}_{\mathrm{CO}_{2}}$ : Partial pressure of $\mathrm{CO}_{2}$.

4. Gibbs free energy of formation for educts and products envolved in the formation of malachite and azurite (standard conditions):

Table A4. Gibbs free energy of formation for educts and products of malachite and azurite formation at $298.15 \mathrm{~K}$ and 1 bar.

\begin{tabular}{cc}
\hline Compounds & $\boldsymbol{\Delta}_{f} \mathrm{G}^{\mathbf{0}}\left[\frac{\mathbf{k J}}{\mathbf{m o l}}\right]$ at $\mathbf{2 9 8 . 1 5} \mathbf{~ K}$ \\
\hline $\mathrm{CuO}[32]$ & -127.6 \\
$\mathrm{CO}_{2(a q)}[16]$ & -385.99 \\
$\mathrm{H}_{2} \mathrm{O}[32]$ & -237.34 \\
$\mathrm{Cu}_{2}(\mathrm{OH})_{2} \mathrm{CO}_{3(s)}[$ malachite] [32] & -906.2 \\
$\mathrm{Cu}_{3}(\mathrm{OH})_{2}\left(\mathrm{CO}_{3}\right)_{2(s)}[$ azurite] [32] & -1439.13 \\
\hline
\end{tabular}




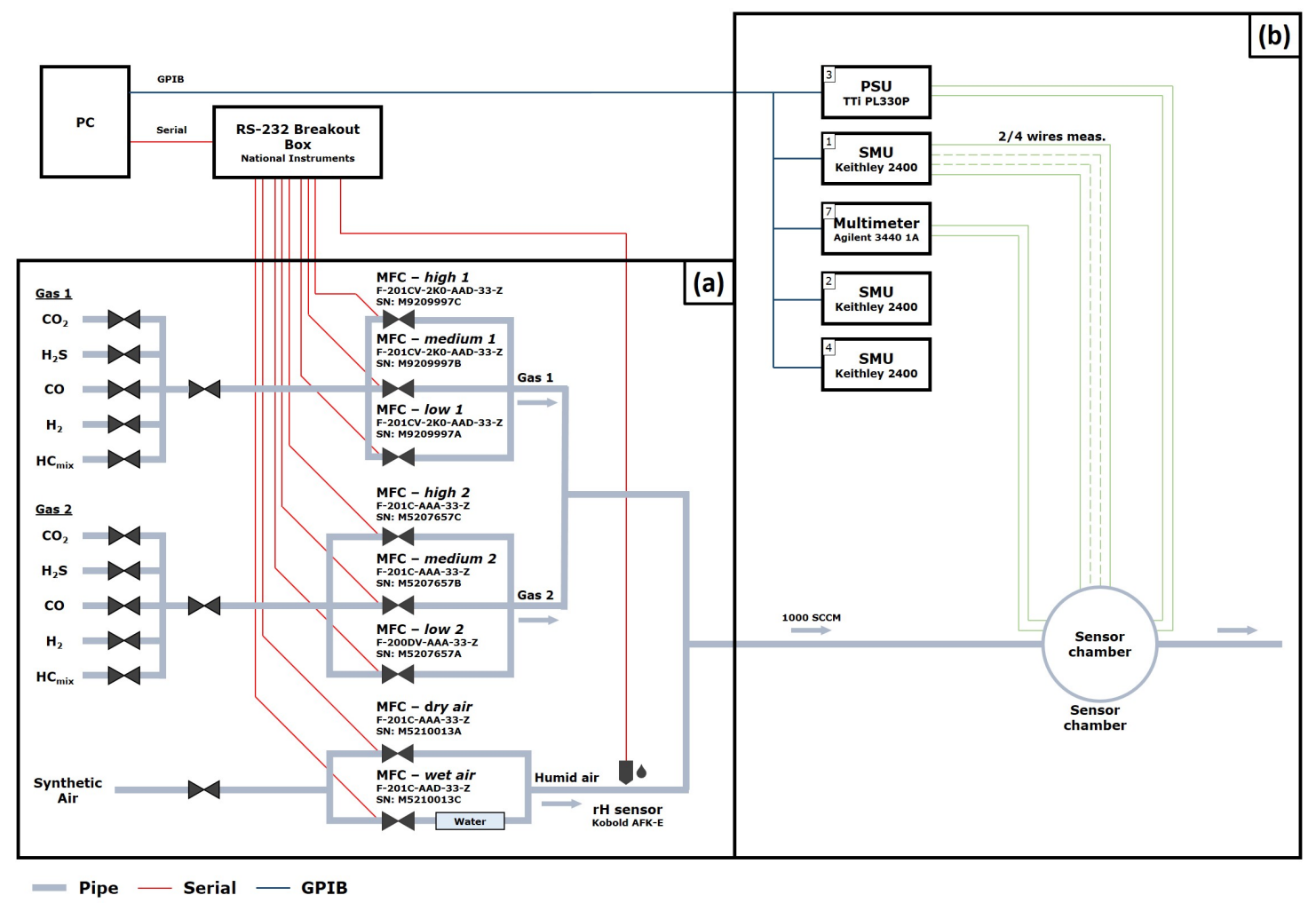

Figure A1. Gas measurement set-up: (a) gas atmospheric part, (b) electrical evaluation part.

\section{References}

1. Pachauri, R.K.; Allen, M.R.; Barros, V.R.; Broome, J.; Cramer, W.; Christ, R.; Church, J.A.; Clarke, L.; Dahe, Q.; Dasgupta, P.; et al. Climate Change 2014: Synthesis Report. Contribution of Working Groups I, II and III to the Fifth Assessment Report of the Intergovernmental Panel on Climate Change; IPCC: Geneva, Switzerland, 2014; p. 28.

2. Ahn, J.; Brook, E.J.; Mitchell, L.; Rosen, J.; McConnell, J.R.; Taylor, K.; Etheridge, D.; Rubino, M. Atmospheric $\mathrm{CO}_{2}$ over the last 1000 years: A high-resolution record from the West Antarctic Ice Sheet (WAIS) Divide ice core. Glob. Biogeochem. Cycles 2011, 26. [CrossRef]

3. Recent Monthly Average Mauna Loa $\mathrm{CO}_{2}, 2018$. Available online: https://www.esrl.noaa.gov/gmd/ ccgg/trends/index.html (accessed on 18 July 2018).

4. Seppänen, O.A.; Fisk, W.J.; Mendell, M.J. Association of Ventilation Rates and $\mathrm{CO}_{2}$ Concentrations with Health andOther Responses in Commercial and Institutional Buildings. Indoor Air 1999, 9, $226-252$. [CrossRef] [PubMed]

5. Nassif, N. A robust $\mathrm{CO}_{2}$-based demand-controlled ventilation control strategy for multi-zone HVAC systems. Energy Build. 2012, 45, 72-81. [CrossRef]

6. Raum-Luftqualitätsfühler QPA10.. QPA20.., 2005. Available online: https://hit.sbt.siemens.com/RWD/ DB/DE/de/Assets/39693.pdf (accessed on 18 July 2018).

7. Ratterman, M.; Shen, L.; Klotzkin, D.; Papautsky, I. Carbon dioxide luminescent sensor based on a CMOS image array. Sens. Actuators B Chem. 2014, 198, 1-6. [CrossRef]

8. Wang, J.; Wen, Z.; Yang, B.; Yang, X. Optical carbon dioxide sensor based on fluorescent capillary array. Results Phys. 2017, 7, 323-326. [CrossRef]

9. Pentyala, V.; Davydovskaya, P.; Ade, M.; Pohle, R.; Urban, G. Carbon dioxide gas detection by open metal site metal organicframeworks and surface functionalized metal organic frameworks. Sens. Actuators $B$ Chem. 2016, 225, 363-368. [CrossRef] 
10. Lorenc, P.; Strzelczyk, A.; Chachulski, B.; Jasinski, G. Properties of Nasicon-based $\mathrm{CO}_{2}$ sensors with $\mathrm{Bi}_{8} \mathrm{Nb}_{2} \mathrm{O}_{17}$ reference electrode. Solid State Ion. 2015, 271, 48-55. [CrossRef]

11. Wang, X.; Qin, H.; Sun, L.; Hu, J. $\mathrm{CO}_{2}$ sensing properties and mechanism of nanocrystalline $\mathrm{LaFeO}_{3}$ sensor. Sens. Actuators B Chem. 2013, 188, 965-971. [CrossRef]

12. Lee, J.; Choi, N.J.; Lee, H.K.; Kim, J.; Lim, S.; Kwon, J.; Lee, S.; Moon, S.; Jong, J.; Yoo, D. Low power consumption solid electrochemical-type micro $\mathrm{CO}_{2}$ gas sensor. Sens. Actuators B Chem. 2017, 248, 957-960. [CrossRef]

13. Abouda, A.; Al-Keleshb, H.; El Roubyc, W.; Farghalic, A.; Hamdedeinc, A.; Khedrc, M. $\mathrm{CO}_{2}$ responses based on pure and doped $\mathrm{CeO}_{2}$ nano-pellets. J. Mater. Res. Technol. 2018, 7, 14-20. [CrossRef]

14. Yadav, A.; Lokhande, A.; Kim, J.H.; Lokhande, C. Enhanced sensitivity and selectivity of $\mathrm{CO}_{2}$ gas sensor based on modified $\mathrm{La}_{2} \mathrm{O}_{3}$ nanorods. J. Alloys Compd. 2017, 723, 880-886. [CrossRef]

15. Tanvir, N.; Yurchenko, O.; Laubender, E.; Urban, G. Investigation of low temperature effects on work function based $\mathrm{CO}_{2}$ gas sensing of nanoparticulate $\mathrm{CuO}$ films. Sens. Actuators B Chem. 2017, 247, 968-974. [CrossRef]

16. Tanvir, N.; Yurchenko, O.; Wilbertz, C.; Urban, G. Investigation of $\mathrm{CO}_{2}$ reaction with copper oxide nanoparticles for room temperature gas sensing. J. Mater. Chem. A 2016, 4, 5294-5302. [CrossRef]

17. Herran, J.; Mandayo, G.; Castano, E. Semiconducting $\mathrm{BaTiO}_{3}-\mathrm{CuO}$ mixed oxide thin films for $\mathrm{CO}_{2}$ detection. Thin Solids Films 2009, 517, 6192-6197. [CrossRef]

18. Debbichi, L.; Marco de Lucas, M.; Pierson, J.; Krüger, P. Vibrational Properties of $\mathrm{CuO}$ and $\mathrm{Cu}_{4} \mathrm{O}_{3}$ from First-Principles Calculations, and Raman and Infrared Spectroscopy. J. Phys. Chem. 2012, 116, 10232-10237. [CrossRef]

19. Deutsche Forschungsgemeinschaft. MAK-und BAT-Werte-Liste 2013: Maximale Arbeitsplatzkonzentrationen und Biologische Arbeitsstofftoleranzwerte. Mitteilung 49; Wiley VCH Verlag GmbH \& Co. KGaA: Weinheim, Germany, 2013; p. 93, doi:10.1002/9783527675135.

20. Steinhauer, S.; Brunet, E.; Maier, T.; Mutinati, G.; Köck, A. Suspended CuO nanowires for ppb level $\mathrm{H}_{2} \mathrm{~S}$ sensing in dry and humid atmosphere. Sens. Actuators B Chem. 2013, 186, 550-556. [CrossRef]

21. Chen, M.; Yue, Y.; Ju, Y. Growth of metal and metal oxide nanowires driven by the stress-induced migration. J. Appl. Phys. 2012, 111, 104305. [CrossRef]

22. Xu, C.H.; Woo, C.H.; Shi, S.Q. Formation of $\mathrm{CuO}$ nanowires on $\mathrm{Cu}$ foil. Chem. Phys. Lett. 2004, 399, $62-66$. [CrossRef]

23. Adilov, S.R.; Afanaciev, V.P.; Kashkul, I.N.; Kumekov, S.E.; Mukhin, N.V.; Terukov, E.I. Studying the Composition and Structure of Films Obtained by Thermal Oxidation of Copper. Glass Phys. Chem. 2017, 43, 272-275. [CrossRef]

24. Abdelmounaïm, C.; Amara, Z.; Maha, A.; Mustapha, D. Effects of molarity on structural, optical, morphological and $\mathrm{CO}_{2}$ gas sensing properties of nanostructured copper oxide films deposited by spray pyrolysis. Mater. Sci. Semicond. Process. 2016, 43, 214-221. [CrossRef]

25. Ishihara, T.; Higuchi, M.; Takagi, T.; Ito, M.; Nishiguchi, H.; Takita, Y. Preparation of CuO thin films on porous $\mathrm{BaTiO}_{3}$ by self-assembled multibilayer film formation and application as a $\mathrm{CO}_{2}$ sensor. J. Mater. Chem. 1998, 8, 2037-2042. [CrossRef]

26. Seguin, M. Thermogravimetric And Differential Thermal Analysis Of Malachite And Azurite In Inert Atmospheres And In Air. Can. Mineral. 1975, 13, 127-132.

27. Korotcenkov, G. Handbook of Gas Sensor Materials, 1st ed.; Springer-Verlag New York: New York, NY, USA, 2013; pp. 273-279.

28. Yang, X.; Kattel, S.; Senanayake, S.; Boscoboinik, J.; Nie, X.; Graciani, J.; Rodriguez, J.; Liu, P.; Stacchiola, D.; Chen, J.G. Low Pressure $\mathrm{CO}_{2}$ Hydrogenation to Methanol over Gold Nanoparticles Activated on a $\mathrm{CeO}_{x} / \mathrm{TiO}_{2}$ Interface. J. Am. Chem. Soc. 2015, 137, 10104-10107. [CrossRef] [PubMed]

29. Iwata, T.; Matsuda, K.; Takahashi, K.; Sawada, K. $\mathrm{CO}_{2}$ Sensing Characteristics of a $\mathrm{La}_{2} \mathrm{O}_{3} / \mathrm{SnO}_{2}$ Stacked Structure with Micromachined Hotplates. Sensors 2017, 17, 2156. [CrossRef] [PubMed]

30. Marsal, A.; Dezanneau, G.; Cornet, A.; Morante, J. A new CO2 gas sensing material. Sens. Actuators B Chem. 2003, 95, 266-270. [CrossRef] 
31. Trung, D.; Toan, L.; Hong, H.; Lam, T.; Trung, T.; Hieu, N. Selective detection of carbon dioxide using $\mathrm{LaOCl}$-functionalized $\mathrm{SnO}_{2}$ nanowires for air-quality monitoring. Talanta 2012, 88, 152-159. [CrossRef] [PubMed]

32. Robie, R.; Waldbaum, D. Thermodynamic properties of minerals and related substances at $298.15 \mathrm{~K}$ $\left(25.0^{\circ} \mathrm{C}\right)$ and one atmosphere (1.013 bars) pressure and at higher temperatures. Available online: https: / / pubs.er.usgs.gov/publication/b1259 (accessed on 22 November 2018).

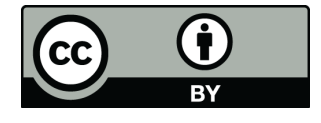

(C) 2018 by the authors. Licensee MDPI, Basel, Switzerland. This article is an open access article distributed under the terms and conditions of the Creative Commons Attribution (CC BY) license (http:/ / creativecommons.org/licenses/by/4.0/). 